ISSN 2073-8994

www.mdpi.com/journal/symmetry

Review

\title{
The First Appearance of Symmetry in the Human Lineage: Where Perception Meets Art
}

\section{Derek Hodgson}

Department of Archaeology, University of York, King's Manor, York, YO1 7EP, UK;

E-Mail: dehogson@googlemail.com

Received: 17 January 2011; in revised form: 23 February 2011 / Accepted: 23 February 2011 / Published: 1 March 2011

\begin{abstract}
Although symmetry may be important for understanding the selection of form in art over the historical period, this preference may have originally stemmed from certain basic perceptual mechanism that initially arose during prehistory. The first signs of an awareness to symmetry can be found in the archaeological record with the arrival of Acheulean handaxes, especially those dating from 500,000 years ago onwards, which are typified by a prodigious bilateral symmetry. As handaxes represent the earliest material record of an interest in symmetry by the human lineage, they provide a privileged means of understanding why this kind of form came to be valued by later human groups, particularly in relation to "art". Although still controversial, the preference for symmetry at such an early date has been linked to various aspects of perception relating to enduring evolutionary factors. In this regard, it will be demonstrated how the preference for symmetrical Acheulean tools arose out of long standing perceptual correlates relating to ecological factors that predated the arrival of hominins.
\end{abstract}

Keywords: visual brain; symmetrical tools; evolution; neuropsychology; proto-art

\section{Introduction}

Symmetry has consistently been identified as important to the appreciation of most forms of visual art, which has been confirmed both by research into the psychology of perception and neuropsychology. This propensity may derive from certain enduring factors associated with the way the visual brain processes information that was mediated by adaptive strategies allowing organisms to survive. The question arises as to exactly when symmetry may have become an attribute that was no 
longer linked purely to either survival or functional demands. In order to answer this question it is first necessary to understand why symmetry initially became vital to survival, which will form the basis for understanding why such an attribute later became fundamental to both tool-making and creative endeavors.

Acheulean tools, which first began to appear in the archaeological record about 1.6 million years ago following the Oldowan sequence [1], constitute the first instance of imposed symmetry and have been associated with a number of hominin species, some of which were probably ancestral to modern humans. In this respect, the symmetry of Acheulean tools was noted over a hundred years ago and has been the subject of intense research ever since [2,3]. The symmetry of late Acheulean tools from around 500,000 BP (before present) seem, however, to display a greater refinement and sophistication compared to earlier examples [4,5] with the profile of the earlier bifaces being accounted for by purely functional determinants [6]. Interestingly, the larger bifaces seem to reveal a bias toward greater symmetry [7]. It has therefore been suggested that the increased concern for symmetry during the later period can be explained by an intentional concern for symmetry that was detached from the practicalities involved in the shaping process. In which case, this would represent the first occasion when symmetry did not depend solely on the perceptual imperatives of survival or on the practicalities of engaging with materials. As this represents the first evidence of a disinterested concern for symmetry, it provides an important clue as to how symmetry became important to visual culture. Having said this, examples of refined symmetrical handaxes have been found before 500,000 BP but these seem to be a much rarer commodity compared to the later period. Moreover, concern for symmetry seems to center on handaxes rather than other Acheulean tools such as cleavers, which may have initially derived from the constraints associated with sharpening procedures and the particular functional demands associated with handaxes. In what follows, the way in which an interest in symmetry for its own sake first evolved and how this became important to "art" will be addressed.

\section{Symmetry Detection in Nonhuman Primates and Humans}

Rensch [8] demonstrated that monkeys, raccoons, and birds prefer symmetry to asymmetry and irregularity. This may be related to the fact that symmetry is an enduring aspect of the visual world that has been incorporated into the underlying neural capacities of the brain in terms of capturing the non-accidental properties of the world $[9,10]$. In this respect, symmetry seems to be a property integral to the natural world [11,12] that, for example, helps promote efficient growth in natural occurring organisms, and also provides a means for the visual brain to offset variability $[13,14]$. Thus, the preferred response of neurons may have originally derived from the fact that many of the objects that need to be detected are themselves symmetrical [14] and thereby serve as an early warning signal that something of interest may need to be attended to. In addition, most biologically important objects are symmetrical $[15,16]$ and, in this regard, sensitivity to symmetry may have evolved because it is crucial for discriminating living organisms from inanimate objects [17]. The existence of fractals in natural scenes also reflects the widespread existence of symmetry in nature [18]. Symmetry therefore appears to provide a useful means by which the visual world can be encoded for the purpose of efficient recognition $[19,20]$. 
The importance of symmetry in this context has been confirmed by neuroimaging studies that show how certain areas of the extrastriate cortex are involved in integrating more basic pattern recognition functions deriving from the early visual cortex (V1 and V2) that are assimilated for more extensive processing in extrastriate areas [21,22]; a finding that has received support and was refined by Sasaki et al. [23] where extrastriate areas V3 V3A, V4, V7, as well as LO, were also implicated in the perception of symmetry (with much stronger activation in V4 and LO). In addition, Sasaki et al found differences between monkeys and humans in the way symmetry is processed in that, although corresponding areas were active in monkeys, this was at a much reduced level (see below for more on this). The authors concluded that sensitivity to symmetry must therefore be crucial to survival e.g., for identifying predators or prey and thus provides evidence of an evolutionary continuity between non-human primates and humans [24,25]. The enhanced sensitivity of humans to symmetry thereby seems to indicate that this is essential for extracting the non-accidental properties of the visual array and is a function that is especially prominent with regard to mirror symmetry [26,27].

The perception of symmetry as an early and rapid means of extracting information from the world also appears to occur automatically at a preattentive level and is unaffected by learning [28-30], which further underpins its importance; a fact that is reinforced by the finding that sensitivity to symmetry appears in infancy [31] and the bias toward symmetry causes particular kinds of misperceptions that remain unbeknown to perceivers [32]. As the participants in such studies remained unaware of the various effects involved, this reinforces the fact that basic perceptual mechanisms associated with implicit processes influence behaviour. Mirror symmetry, especially along the vertical axis, is also perceived more effortlessly and spontaneously than other kinds of symmetry and does not always involve conscious awareness when compared to symmetries that necessitate rotation and translation [16,33]. Having set out the importance of symmetry for perceiving the world in relation to the visual brain, we now need to consider how such findings can help to explain the symmetry of Acheulean tools.

\section{Symmetry Detection, Acheulean Handaxes, and the Brain}

A typical Acheulean stone handaxe consists of the classic teardrop shape that displays an obvious concern for symmetry (see Figures 1 and 2) with considerable quantities having been found throughout the world, including Africa and the Middle East [34]. Although first appearing around 1.6 million years ago, such tools endured up until approximately 200,000 BP and, in some instance, even later, and therefore represent the longest known "tradition" [1]. The shape of earlier Acheulean tools seem, however, to be less refined than those from about 500,000 BP (although what are termed "occasionals" appear before this period [35] (see, for example, Figure 1), when not only was there a greater concern for mirror symmetry but also more complex kinds of symmetries began to appear, such as twisted and broken symmetry [4]. One remarkable feature of this concern was that it continued for a prolonged period over such a vast area, which has led some scholars to suggest that symmetry arose coincidentally from the knapping or resharpening procedure [6,36-38]. A growing consensus nevertheless contends that, with the arrival of more refined handaxes, symmetry became somewhat more detached from functional dictates in that a disinterested or more derived awareness toward 
symmetry tended to come to the fore [4,5,39-43]. As will be demonstrated, this consensus is supported by evidence from perceptual theory and brain functioning.

Figure 1. Two sides of an Acheulean handaxe from South Africa (ironstone $127 \mathrm{~mm} \times 248 \mathrm{~mm}$ ) showing the prodigious symmetry-the right hand view incorporates a mirrored Bezier curve to highlight the degree of symmetry. This example represents an "occasional" that predates the symmetrical handaxes which began to appear with greater frequency after 500,000 BP. Dated by association with tooth-plates of the extinct Elephas Reckii Reckii, or Reck's Elephant to approximately 750,000 BP [44].

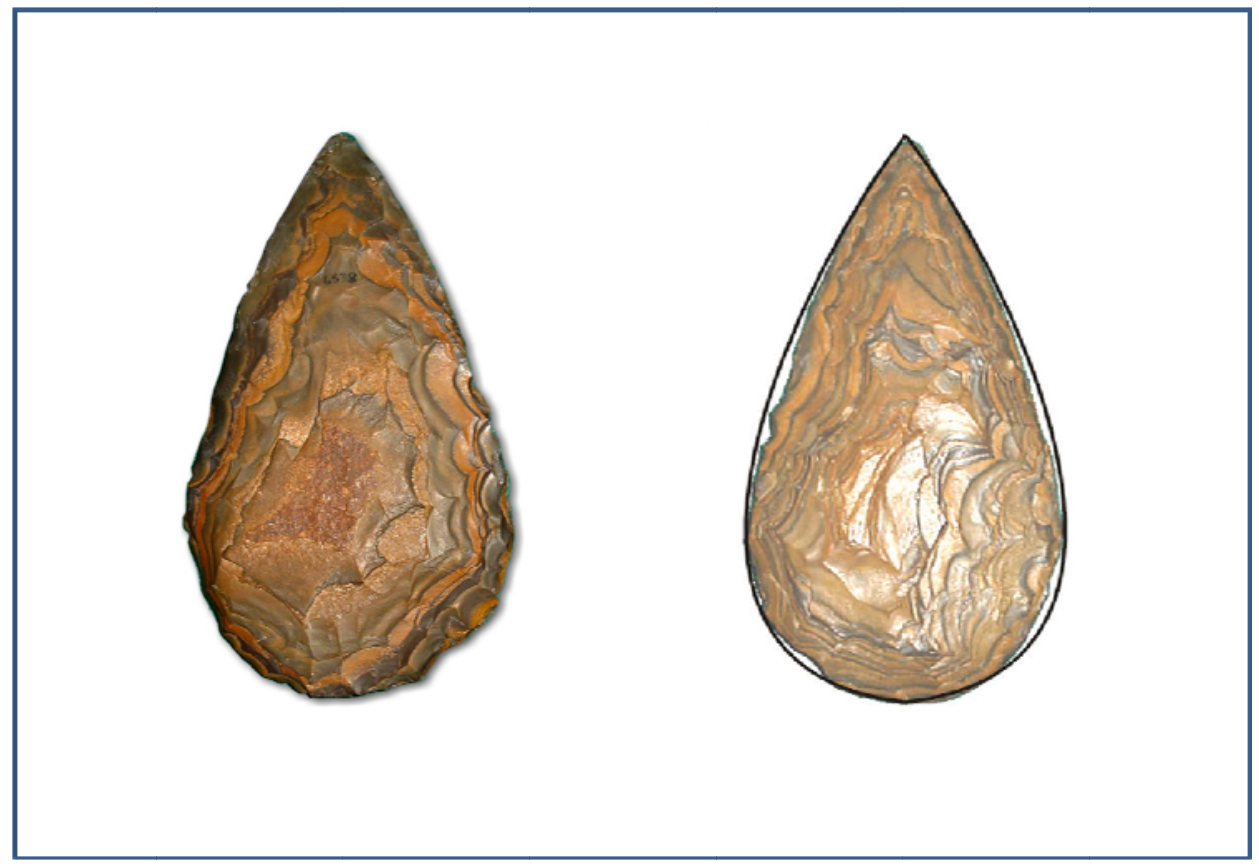

Figure 2. A selection of Elandsfontein handaxes, made of silcrete, quartz porphyry, and quartz dating to between 700,000 to 400,000 BP showing how symmetry was conserved despite the difference types of materials employed [45].
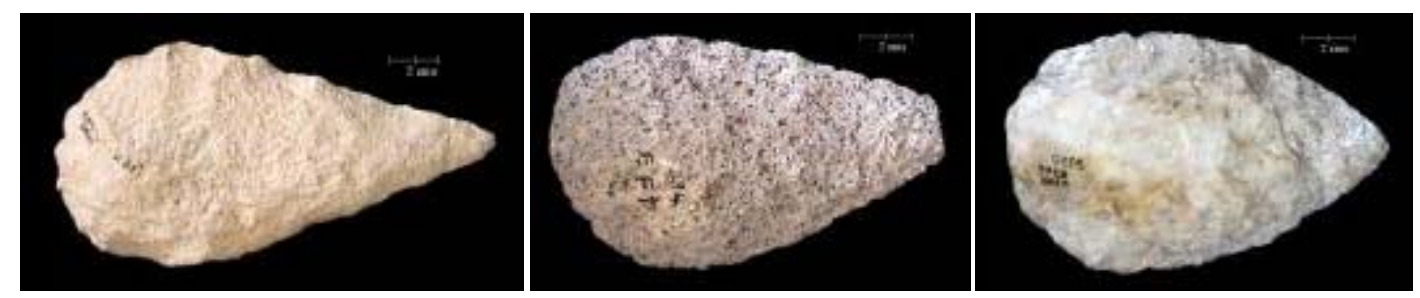

Although Kohn and Mithen [46] have attempted to explain this more disengaged interest by way of sexual selection and mate preference, this has come under increasing criticism on a number of counts [47-50]. The alternative explanation proposes that the symmetry of Acheulean handaxes should be regarded as a by-product of the general perceptual processes as outlined above. Enquist [14,51] for example, has shown that the preference for symmetry may derive from fundamental properties relating to how the visual brain functions that has incorporated the associated affordances into general perceptual mechanisms. The detection of symmetry may also be related to prototypes in that symmetry, 
in its broadest sense, is an indication that something remains the same despite change. In this sense, such an analysis of symmetry has significance for understanding Acheulean tools in that, in order to make a tool, one has to remain alert to the fact that, although an object may undergo transformation through rotation, there are crucial aspects of form that remain unchanged [52].

These observations can be linked to how visuo-spatial information is processed by the brain. Although information from early visual cortex is directed towards the superior parietal area (along the dorsal-dorsal pathway) and intraparietal sulcus (IPS) (along the ventro-dorsal pathway) in both humans and monkeys, the difference seems to reside in the way shape is processed. This is corroborated by the fact that, in macaque IPS, sensitivity to shape seems more concerned with two-dimensional aspects of form than the equivalent area in humans that is more attuned to three-dimensional parameters [53-56]. This finding is reflected in the fact that the processing of shape in this region is more cue invariant in humans i.e., there is a greater capacity to cope with variability in shape profile [53] that seems to have helped facilitate the production of both the first hominin tools during the Oldowan and the later more complex Acheulean tools.

In terms of how the brain exploits such information for producing tools, the factors that initially gave rise to earlier Acheulean bifaces seem initially to have relied on preattentive and implicit processes mediated by the visuo-spatial/motor pathway involving the extrastriate $\rightarrow$ intraparietal ventro-dorsal stream that underwent enhancement compared to non-human primates. This may have served to scaffold the later more explicit concern for symmetry in that the consciously derived ventral pathway (for explicit visual recognition) was becoming more interconnected with implicit or embodied mechanisms [57]. In this respect, as well as the extrastriate regions already alluded to, evidence suggests that some of the above mentioned areas i.e., V4, V3A and V7, may be linked to the parieto-occipital region through the intraparietal sulcus - which also seems to have undergone enhancement/enlargement in humans - for processing 3D shape from motion for the purpose of manipulating tools [56,58]. Crucially, beyond the early regions of the visual cortex, symmetry has been implicated in the later/higher area of the intraparietal sulcus where 3D shape from motion is processed relating to mental rotation and object constancy [59], which has also been associated with manipulating and attending to tools in connection with the ventro-dorsal stream for processing visuo-spatial/motor information [56,58,60-62].

Stout [63] and associates investigations using brain scans suggest that the making of Oldowan tools by expert rather than novice knappers requires a greater interaction of pathways, involving enhanced visuo-spatial and motor coordinates, that seem to come together in the supramarginal gyrus (SMG) in inferior parietal cortex. Importantly, this interaction would have been increasingly important for the production of the more complex symmetries of late Acheulean bifaces in that such symmetries required a greater involvement of the inferior parietal area. This suggests that, in order to produce the later more refined Acheulean bifaces, further integration of visual information initially arising from the occipital area (which projects to the ventral premotor area initially through the ventro-dorsal pathway) eventually led to interconnections forming between AIP and SMG (see Figure 3). This scenario has recently received support from a study showing how, not only is the intraparietal sulcus involved in simply tool use in humans, but also the aSMG (anterior supramarginal gyrus) - a cortical area that does not seem to exist in non-human primates [64]. It is therefore no coincidence that Stout and associates found that SMG became more active when expert knappers were engaged in making tools. 
The ability to produce early to late Acheulean tools may therefore have been contingent on the primitive ventro-dorsal IPS to inferior frontal pathway, which initially formed links with the ventral pathway of the temporal cortex by way of aSMG as Peeters et al. [64] suggest, that later interfaced with fronto-parietal structures as part of the mirror neuron system as illustrated in Figure 3.

Figure 3. The implicit "what/how" enhanced dorsal reach-grasp circuit in the human brain as indicated by the red, blue, and yellow dashed lines, which although shared with non-human primates, did not undergo enhancement for dealing with complex visuo-spatial demands in the latter species e.g., 3D shape from motion. The ventral conscious "what" pathway (green dotted lines) is associated with consciously disposed aspects of tool use regarding the ability to use more composite and a greater range of tools for different tasks. The two smaller ellipses show the location of mirror neuron centres that relate to social aspects of learning to make and use tools.

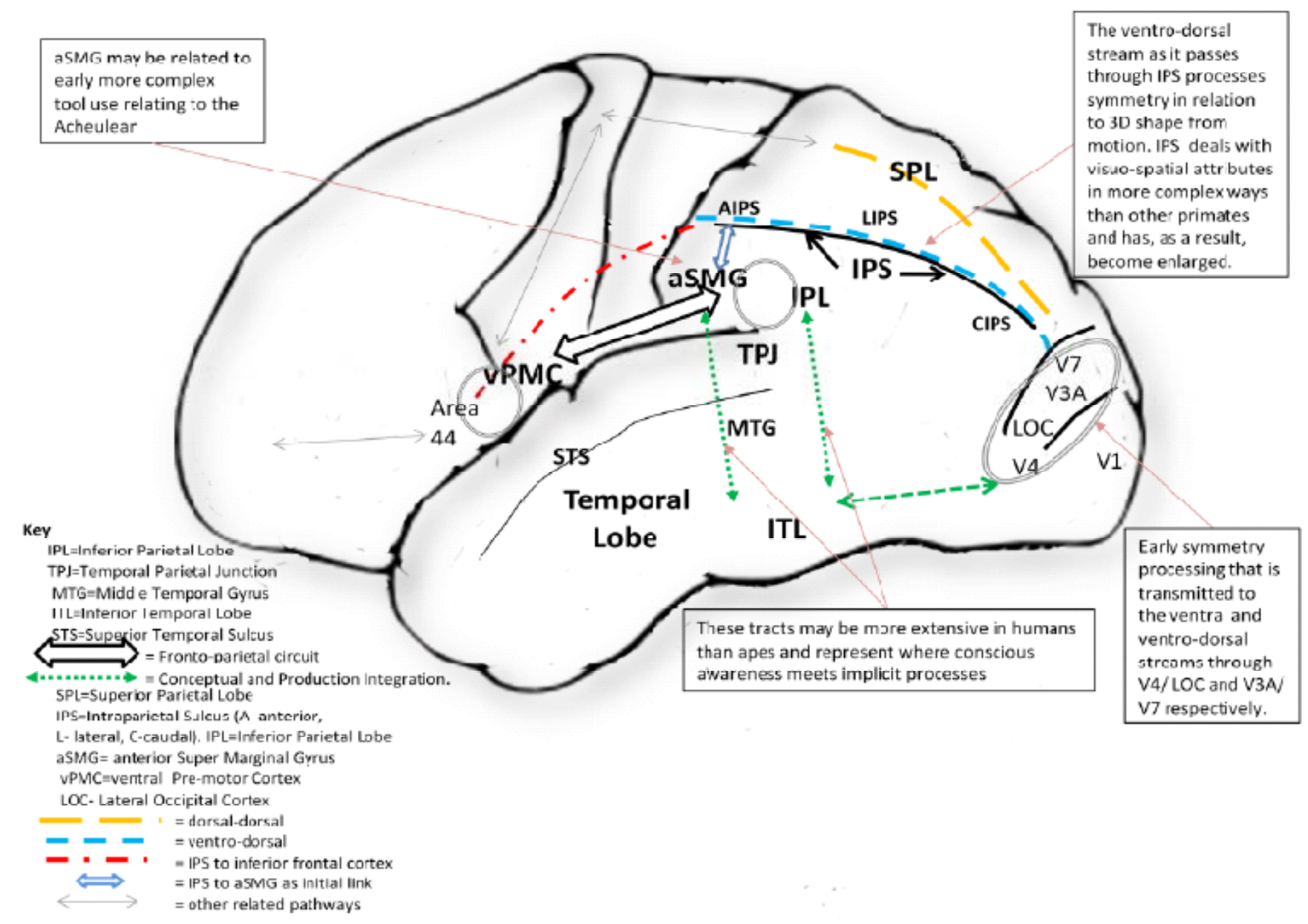

As the ventral premotor cortex in the forward area of the fronto-parietal system has strong reciprocal links with IPL to which the ventro-dorsal pathway (i.e., the where/how stream) converges by way of fronto-parietal connections [65], this has obvious implications in terms of the increased abilities afforded to humans thanks to a fuller interlinking of the various contingencies identified with a greater level of control. As a result of the more complete level of integration of these various pathways, the action affordances arising allowed objects to be manipulated and acted upon with greater effectiveness, as is demonstrated by the distributed neural networks in humans involving the above 
cited areas with regard to the planning and execution of actions when using tools [66]. Figure 3 illustrates the extent of the connecting neural tracts in humans. This is further supported by the fact that, in order to be able to use tools beyond which chimpanzees are capable, involving increased ability to shape materials with more structured strategies, skills are required that recruit the fronto-parietal circuit. The inferior parietal area may therefore represent a crucial point where the "what" and "where/how" as well as the mirror system intersect to enable the production and use of more complex tools, including those with greater symmetry, as part of a left lateralized system employing conceptually mediated abilities [66-68]. The interaction of such factors seems to have become particularly prominent during the late Acheulean that eventually led to the ability to intentionally direct the course of innovation in ways that increasingly benefitted those involved [69], which is obvious in the ability to produce more complex handaxes with twisted symmetry and the highly crafted javelin-like 400,000 year old wooden spears from Schoeningen [4,5]. Thus, symmetry as well as being an important lower order perceptual feature for discriminating objects, is also crucial in a more general sense at later processing stages of the brain for achieving object constancy in the face of changeespecially when mental rotation is required, which is vital for producing the refined symmetry of later Acheulean tools.

Interestingly, a typical Acheulean handaxe displays mirror symmetry along its foremost axis (see Figure 1) that is manifest in the obvious bilateral symmetry that corresponds to the vertical axis of the mirror symmetry to which the human visual system is particularly attuned. This provides additional evidence that the tendency towards symmetry in the first handaxes was constrained by practical determinants and implicit visuo-spatial/motor attributes relating to the extrastriate $\rightarrow$ intraparietal ventro-dorsal stream.

\section{Perceptual Fluency, Neural Synchrony, and Aesthetics}

The foregoing suggests symmetry is fundamental to visual perception and is automatic and was initially mediated by a dedicated neural system in LOG and related structures including the intraparietal sulcus [57]. The evolution of this network meant the Homo erectus was pre-adapted to produce symmetrical tools, which accounts for the relative uniformity in shape over such a long period. It may be this pre-adaptation that formed the basis on which more complex tool morphologies came to be based, especially during the latter part of the Acheulean period and on which a more detached response led to the non-functional features that began to appear with such bifaces [40,70]. Importantly, it has been established that the affordances associated with symmetry can generalize to other situations in that preference and interest in symmetry in contexts other than the determining situation can direct interest as a by-product thereby allowing an "aesthetic" response to occur. The "aesthetic" referred to here, however, is closely aligned to the concept of "perceptual fluency" proposed by Reber [71,72], whereby symmetry not only serves as an important cue for parsing the visual array but also allows objects to be processed with greater speed and efficiency. This also reflects ease of perception for realising successful recognition that is associated with positive affect. The attraction to symmetry was therefore likely to have originally derived from underlying perceptual/recognition processes that were exapted as a by-product of perceptual fluency [73] with sensory exploitation also playing a role [74]. This idea is further encapsulated in the following 
statement, "The more fluently the perceiver can process an object, the more positive is his or her aesthetic response" [72]. What is of particular interest here concerns the introduction of the aesthetic component, the significance of which will now be discussed.

Recent studies into how the brain processes information have shown that perceptual fluency is likely to be mediated by attractor neural networks where repeated incoming visual signals are processed more efficiently that result in a streamlining of neural firing rates [75]. This also appears to be related to increased synchronization of the neurons associated with correctly identifying a stimulus [76]. Similarly, it has been demonstrated that exposure to several exemplar dot patterns from a category leads to faster and more fluent visual processing of the associated prototype that is reflected in activation in the posterior occipital cortex [71,77]. Thus, the positive response to fluency that is associated with symmetry may result from the fact that this signifies error-free processing as well as the availability of knowledge for identifying a potential threat $[72,78,79]$ that can give rise to an aesthetic effect due to the increased synchronisation in neuron activity.

The importance of symmetry in relation to aesthetic determinants is underlined by the fact that symmetry is aesthetically pleasing compared to complexity despite certain interactive effects [80]. Such effects show how other dimensions of interest can exert an influence that can give rise to elaborate responses to different kinds of form or pattern, which may serve as the basis for more culturally derived factors [81]. In this regard, patterns perceived as midway between simple to complex tend to be regarded as more aesthetically pleasing according to the previous level of complexity towards which a person has already become accustomed [82-84]. Notwithstanding such interactive effects, empirical research on aesthetics has found that symmetry, when compared to nonsymmetrical forms, is particularly robust when aesthetic judgments are made $[60,85]$. It is also highly significant that, similar to when a stimulus is successful perceived, aesthetic responses also lead to synchronisation and sparse coding of neural networks that resonate in response to the presenting stimulus [86]. Aesthetic responses may therefore be intimately connected to positive affect in the sense that "prototypical stimuli feel familiar, regardless and independent of whether they have been seen before, and this feeling is also associated with positive affect" [87]. It is the connection between the perceptual fluency-positive affect and neural synchrony on the one hand, and symmetry/aesthetic responses on the other that provides a useful link for understanding the standardisation of Acheulean bifaces.

A productive approach to understanding the significance of the shape of Acheulean handaxes would thus be to regard the non-functional aspects of symmetry as a by-product of general perceptual and recognition processes that serve to encode the various regularities of the world. The symmetry of later Acheulean tools may therefore constitute evidence of the beginning of an explicit conscious awareness of an ability to impose form on inert matter [73], and can be regarded as a kind of stimulus generalisation associated with a bias for prototypicality/symmetry where key aspects of form underwent exaggeration and intensification in order to produce what is referred to as a super stimulus. This finding is compatible with the suggestion that averageness/prototypicality, when combined with a preference for symmetry, is closely tied to perceptual correlates, as indicated, that may have given rise to a concern for the non-functional aspects of Acheulean handaxe shape. This also dovetails with Machin's [88] view that Acheulean bifaces were not solely based on practical demands in that they 
suggest an "aesthetic" interest, which may also be related to social display [89] that could have served as a basis for boundary marking activities $[90,91]$.

The non-functional symmetry of Acheulean bifaces could thereby have initially been based on a bias of the human perceptual system for perceiving symmetrical/prototypical objects as part of a more consciously disposed creative engagement with the world. Crucially, not only has symmetry perception been linked to the intraparietal sulcus as part of the visuo-spatial/motor pathway, but has also been implicated in aesthetic judgements that, in turn, have been associated with the social abilities of the more forward areas of the brain in the sense that the aesthetic activity observed in the intraparietal area was found to overlap with both the appreciation of symmetry and social criteria $[60,92]$. This finding suggests that aesthetic awareness engages social abilities by way of the intraparietal sulcus and thus provides further confirmation that the exacting symmetry of later Acheulean handaxes was most likely linked to a proto-aesthetic sense. Additional evidence as to the existence of such an ability is to be found in the fact that some handaxes are obviously too large to be of any practical use, e.g., the Furze Platt biface (see Figure 4) and similar overly large handaxes that display a high degree of symmetry [93-95], which is related to the concept of a super stimulus as cited above.

Figure 4. The Furze Platt handaxe from Maidenhead, England, ca. 300,000 BP. This handaxes is $39.5 \mathrm{~cm}$ in length weighing 7.5 pounds and is regarded as too large and heavy to be of any practical use yet displays a prodigious symmetry [96].

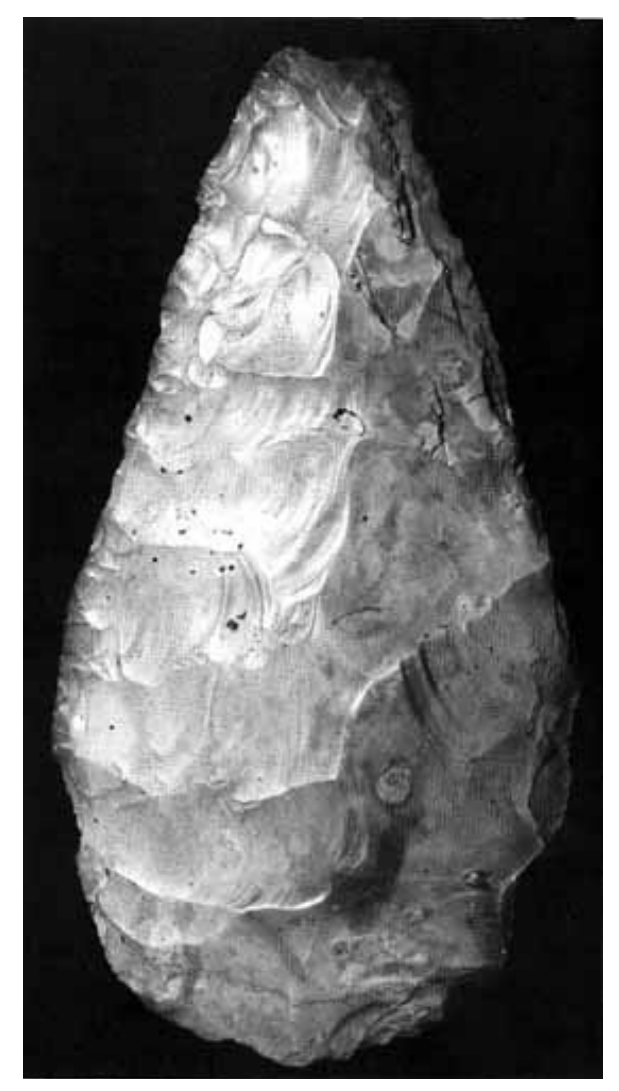

Although such an interest in symmetry may constitute evidence of an incipient aesthetic sense $[40,57,73]$, this may also be linked to quasi-ritualistic tendencies [49]. In this respect, Radomsky 
and Rachman [97] have proposed that, "It is suggested that compulsive ordering and a drive for symmetry are extreme manifestations of the common preference for order and symmetry". The preference for symmetry is therefore thought to derive from the need to avoid disorder and uncertainty in a striving towards reassurance that is probably mediated by genetic and neuropsychological processes [97-100]. This tendency also seems to be intimately related to positive affect/perceptual fluency and, to some extent, can account for the apparent overproduction and random discard of many unused Acheulean handaxes.

These insights suggest that perhaps as early as 500,000 BP, our early ancestors were already becoming engaged with and consciously disposed towards symmetry. In this sense, instead of simply being an outcome of functional considerations and implicit perceptual processes, symmetry became a source of disengaged interest whereby previous constraints were exapted for purposes other than originally intended. In other words, symmetry began to serve as a focus for social and/or aesthetic concerns. The question of why symmetry became so important in relation to handaxes rather than other Acheulean tools, such as cleavers, can be answered by proposing that the functional demands relating to the making of handaxes as bifaces would have been more apparent to the makers concerned. This is because handaxes tend to be more bifacially worked whereas cleavers (see Figure 5) were also produced employing unifacial knapping procedures, which suggests handaxes would have undergone rotation more often than cleavers and would, therefore, have facilitated a greater awareness of symmetry. The outline contour of handaxes is also less complex than for cleavers that would have also allowed symmetry to be more easily defined.

Figure 5. Example of an Acheulean Cleaver [101].

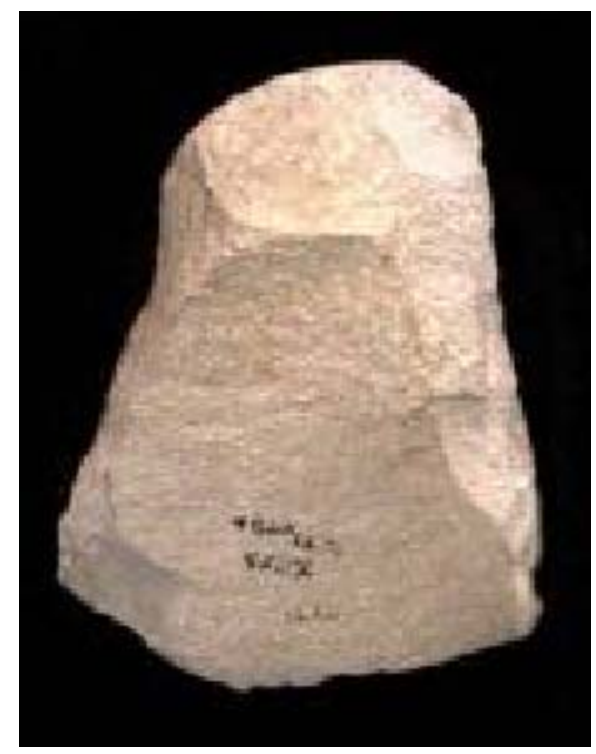

\section{Implications of Symmetry for Understanding Visual Culture}

Tyler [21,22] notes that the artificial environment constructed by humans is full of symmetry that also extends to visual art. As stipulated, the beginning of the tendency towards manipulating the environment in this way seems to have begun with later Acheulean handaxes in the increasing engagement with symmetry as an end in itself. Following the Acheulean period, however, tools 
became even more sophisticated in that a greater range of tools for specific tasks as well as composite implements began to appear in the archaeological record that eventually led to tools with obvious decorative elements. The makers of later symmetrical Acheulean handaxes, although not fully aware of the significance of symmetry, were at least sufficiently alert to begin to respond to its attributes in a way that did not completely rely on preattentive processes. This indicates that the symmetry of Acheulean tools was first exploited on a purely practical/functional level after which a non-functional interest became apparent that arose out of the demands of the perceptual system as embodied in the early visual cortex. The fact that the first glimmerings of an "aesthetic" concern occurred at least $500,000 \mathrm{BP}$ in a species that was not fully modern (either late Homo erectus or Homo heidelbergensis) suggests that the aesthetic sensibility of modern humans has extremely ancient beginnings. This propensity, however, was based on a predetermined sensory bias that engendered feelings of pleasure [102] that eventually led to what Dissanyake [103,104] has termed "making special" or "artification", and is a conclusion that supports the long held belief of Oakley [105] and others [106] that some Acheulean tools were concerned with more than just functional considerations.

\section{Conclusions}

Acheulean tools represent the first occasion when symmetry became detached from adaptive perceptual constraints or functional determinants. This augmented interest seems to have evolved as a by-product of enduring perceptual mechanisms for the detection of important forms in that such symmetry came to transcend practical concerns. Such interest appears to have derived from an assimilation of the implicit visuo-spatial/motor ventro-dorsal pathway with the more consciously derived ventral pathway for processing visual information. More generally, the increased interconnectedness and density of the neural tracts of the evolving human brain may also have been involved, as this served to improve both the rate and amount of cross-referencing that could take place between various parts of the cortex. The procedure whereby symmetry came to transcend functional constraints can thus be summarized as follows: (1) Positive affect deriving from the incidental production of symmetrical handaxes resulting in perceptual fluency that led to, (2) increased synchronization in neural responses that gave rise to, (3) sensory exploitation of symmetry that engendered, (4) a rudimentary aesthetic sense that was, (5) integrated into social signaling. The very beginning of visual culture, which formed the basis for much later "art", therefore appears to have deep roots, and began with an interest in symmetry that went beyond mere functional considerations as is testified by the detached concern for the shape of Acheulean handaxes.

\section{References and Notes}

1. Lycett, S.J.; Gowlett, A.J. On questions surrounding the Acheulean "tradition". World Archaeol. 2008, 40, 295-315.

2. Schmidt, R.R. The Dawn of the Human Min; Sidgwick \& Jackson: London, UK, 1936.

3. Schick K.D.; Toth, N. Making Silent Stones Speak: Human Evolution and the Dawn of Human Technology; Weidenfeld and Nicolson: London, UK, 1993.

4. Wynn, T. Archaeology and cognitive evolution. Behav. Brain Sci. 2002, 25,389-438. 
5. Wynn, T. The Large Cutting Tools from the South African Acheulean and the Question of Social Traditions. Curr. Anthropol. 2004, 45, 672-673.

6. Nowell, A. Coincidental factors of handaxe morphology. Behav. Brain Sci. 2002, 25, 413-414.

7. Toth, N. The Prehistoric Roots of a Human Concept of Symmetry. Symmetry Cult. Sci. 1990, 1, 257-281.

8. Rensch, B. Die Wirksankeit äesthetischer Faktoren bei Wirbeltieren. Z. Tierpsychol 1958, 15, 447-461.

9. Baylis, G.C.; Driver, J. Perception of symmetry and repetition within and across visual shapes: Part-descriptions and object-based-attention. Vis. Cogn. 2001, 8, 163-196.

10. Dragoi, V.; Turcu, C.M.; Sur, M. Stability of cortical responses and the statistics of natural scenes. Neuron 2001, 32, 1181-1192.

11. van der Helm, P.A.; Leeuwenberg, E.L.J. Goodness nontransformational approach. Psychol. Rev. 1996, 103, 429-456.

12. van der Helm, P.A.; Leeuwenberg, E.L.J. Accessibility, a criterion for regularity and hierarchy in visual pattern codes. J. Math. Psychol. 1991, 35, 151-213.

13. van der Helm, P.A. Natural selection of visual symmetries. Behav. Brain Sci. 2002, 25, 422-423; 432-438.

14. Enquist, M.E.; Arak, A. Symmetry, beauty and evolution. Nature 1994, 372, 169-172.

15. Giurfa., M.; Eichmann, B.; Menzel, R. Symmetry perception in an insect. Nature 1996, 382, $458-546$.

16. Wagemans, J. Characteristics and models of human symmetry detection. Trends Cogn. Sci. 1997, 1, 346-352.

17. Tyler, C.W.; Baseler, H.A.; Kontsevich, L.L.; Likova, L.T.; Wade, A.R.; Wandell, B.A. Predominantly extra-retinotopic cortical response to pattern symmetry. NeuroImage 2005, 24, 306-314.

18. Redies, C.; Hasenstein, J.; Denzler, J. Fractal-like image statistics in visual art: similarity to natural scenes. Spatial Vis. 2007, 21, 137-148.

19. Liu, Z.; Kersten, D. Three-dimensional symmetric shapes are discriminated more efficiently than asymmetric ones. J. Opt. Soc. Am. 2003, 20, 1331-40.

20. Vetter, T; Poggio, T; Bültoff, H.H. The importance of symmetry and virtual views in three-dimensional object recognition. Curr. Biol. 1994, 4, 18-23.

21. Tyler, C.W. The Perception of Symmetry and its Computational Analysis; Erlbaum: NJ, USA, 1996.

22. Tyler, C.W; Baseler, H.A.; Kontsevich, L.L.; Likova, L.T.; Wade, A.R.; Wandell, B.A. Predominantly extra-retinotopic cortical response to pattern symmetry. NeuroImage 2005, 24, 306-314.

23. Sasaki' Y.; Vanduffel, W.; Knutsen, T.; Tyler, C.; Tootell, R. Symmetry activates extrastriate visual cortex in human and nonhuman primates. PNAS 2005, 102, 3159-3163.

24. Sasaki, Y. Processing local signals into global patterns. Curr. Opin. Neurobiol. 2007, 17, 132-139.

25. Tyler, C.W. Empirical aspects of symmetry perception. Spatial Vis. 1995, 9, 1-7. 
26. Barlow, H.B.; Reeves, B.C. The versatility and absolute efficiency of detecting mirror symmetry in random dot displays. Vision Res. 1979, 19, 783-793.

27. Beck, D.M.; Pinsk, M.A.; Kastner S. Symmetry perception in humans and macaques. Trends Cogn. Sci. 2005, 9, 405-406.

28. Julesz, B. Figure and ground perception in briefly presented isodipole textures. In Perceptual Organization; Kubouy, M., Pomerantz, J., Eds.; Erlbaum: NJ, USA, 1981; pp. 27-54.

29. Rentschler, I.; Jüttner, M.; Unzicker, A.; Landis, T. Innate and learned components of human visual preference. Curr. Biol. 1999, 9, 665-671.

30. Locher, P.J.; Wagemans, J. Effects of element type and spatial grouping on symmetry detection. Perception 1993, 22, 565-587.

31. Humphrey, G.K.; Humphrey, D.E. The role of structure in infant visual pattern perception. Can. J. Psychol. 1989, 43, 165-182.

32. Stucchi, N.; Graciô, V.; Toneatto, C.; Scocchi, L. The perceptual salience of symmetrical and asymmetrical sections of a line. Perception 2010, 39, 1026-1042.

33. Treder, M.S. Behind the Looking-Glass: A Review on Human Symmetry Perception. Symmetry 2010, 2, 1510-1543.

34. Goren-Inbar, N.; Sharon, G. Axe Age: Acheulian Tool-making from Quarry to Discard; Equinox: London, UK, 2006.

35. McNabb, J.; Binyon, F.; Hazelwood. L. The Large Cutting Tools from the South African Acheulean and the Question of Social Traditions. Curr. Anthropol. 2004, 41, 653-677.

36. Brumm, A.; McLaren, A. Scraper reduction and "imposed form" at the Lower Palaeolithic site of High Lodge, England. J. Hum. Evol. 2010, 2, 185-204.

37. McPherron, S.P. Handaxes as a measure of the mental capabilities of early hominids. $J$. Archaeol. Sci. 2000, 27, 655-663.

38. White. M.J. On the significance of Acheulean bifaces variability in Southern Britain. Proc. Prehist. Soc. 1998, 64, 15-44.

39. Machin, A.J.; Hosfield, R.T; Mithen. S.J. Why are some handaxes symmetrical? Testing the influence of handaxe morphology on effectiveness. J. Archaeol. Sci. 2007, 34, 883-893.

40. Le Tensorer, J.M. Les cultures acheuléennes et la question de l'émergence de la pensée symbolique chez Homo erectus à partir des données relatives à la forme symétrique et harmonique des bifaces. C. R. Palevol. 2006, 5, 135-172.

41. Wenban-Smith, F.F. Biface Typology and Lower Paleolithic Cultural Development: Ficrons, Cleavers and Two Giant Bifaces from Cuxton. Lithics 2004, 25, 11-21.

42. Mallol, C. The Selection of Lithic Raw Material in the Lower and Middle Pleistocene Levels TD6 and TD10 of Gran Dolina (Sierra de Atapuerca, Burgos, Spain). J. Anthropol. Res. 1999, 55, 385-407.

43. Saragusti, I.; Karasik, A.; Sharon, I.; Smilansky. U. Symmetry and roughness of pre-historical tools: Archaeological evidence on the development of the human capability to produce symmetric and smooth-edged tools during the Lower Paleolithic. Presented at Kimmel Centre for archaeological studies, the Weizmann Institute of Science, Israel, 2004.

44. Illustration from the McGregor Museum, Kimberley. Photo Michael Cope ${ }^{\complement}$. 
45 Illustration from Marshall, G.D., Gamble, C.G., Roe, D.A., and Dupplaw, D. 2002. Acheulian biface database, Available at: http://ads.ahds.ac.uk/catalogue/specColl/bifaces/bf_query.cfm ADS, York. (Accessed on 20 February 2011)

46. Kohn, M.; Mithen, S.; Handaxes: products of sexual selection? Antiquity 1999, 73, 518-526.

47. Machin, A.J. Why Bifaces Just Aren't That Sexy: A Response to Kohn and Mithen (1999), Antiquity 2008, 82, 761-769.

48 Nowell, A.; Chang, M.L. The case against sexual selection as an explanation of handaxe morphology. Paleoanthropology 2009, 77-88. Available at: http://www.paleoanthro.org/journal/ contents_dynamic.asp?volume=2009 (Accessed on November 3, 2010).

49. Hodgson, D. Symmetry and humans: Reply to Mithen's "Sexy Handaxe Theory". Antiquity 2009, 83, 195-198.

50. Hodgson, D. Another side of symmetry: the Acheulean biface debate. Antiquity 2010, 84, 325.

51. Enquist, M.; Johnstone, R.A. Generalization and the evolution of symmetry preferences. Proc. $R$. Soc. Lond. B 1997, 264, 1345-1348.

52. Grill-Spector, K.; Kushnir, T.; Edelman, S.; Avidan, G.; Itzchak, Y.; Malach, R. Differential processing of objects under various viewing conditions in the human lateral occipital complex. Neuron 1999, 24, 187-203.

53. Denys, K., Vanduffel, W.; Fize, D.; Nelissen, K.; Peuskens, H.; Van Essen, D.; Orban, G.A. The Processing of Visual Shape in the Cerebral Cortex of Human and Nonhuman Primates: A Functional Magnetic Resonance Imaging Study. J. Neurosci. 2004, 24, 2551-2565.

54. Orban, G.A., Van Essen, D.; Vanduffel. W. Comparative mapping of higher visual areas in monkeys and humans. Trends Cogn. Sci. 2004, 8, 315-324.

55. Orban, G.A., Sunaert, S.; Todd, J.T.; van Hecke P.; Marchal, G. Human cortical regions involved in extracting depth from motion. Neuron 1999, 24, 929-940.

56. Orban, G.A.; Claeys, K.; Nelissen, K.; Smans, R.; Sunaert, S.; Todd, J.T. Mapping the parietal cortex of human and non-human primates. Neuropsychol 2006, 44, 2647-2667.

57. Hodgson, D. Hominin Tool Production, Neural Integration, and the Social Brain. Hum. Origins 2011, in press.

58. Vanduffel, W.; Fize, D.; Peuskens, H.; Denys, K.; Sunaert, S.; Todd, J.T.; Orban, G.A. Extracting 3D from motion: Differences in human and monkey intraparietal cortex. Science 2002, 298, 413-415.

59. Schendan, H.E.; Stern, C.E. Mental rotation and object categorization share a common network of prefrontal and dorsal and ventral regions of posterior cortex. NeuroImage 2007, 35, $1264-1277$.

60. Jacobsen, T.; Schubotz, R.I.; Höfel, L.; van Cramon, D.Y. Brain correlates of aesthetic judgment of beauty. NeuroImage 2006, 29, 276-285.

61. Tzagarakis, C.; Trenton A.; Jerde, T.A.; Lewis, S.M.; Uğurbil, K.; Georgopoulos. A.P. Cerebral cortical mechanisms of copying geometrical shapes: a multidimensional scaling analysis of fMRI patterns of activation. Exp. Brain Res. 2009, 194, 369-380.

62. Nakahara, K.; Adachi, Y.; Osada, T.; Miyashita, Y.; Exploring the neural basis of cognition: multi-modal links between human fMRI and macaque neurophysiology, Trends Cogn. Sci. 2007, 11, 84-92. 
63. Stout, D.; Chaminade. T. The evolutionary neuroscience of toolmaking. Neuropsychologia 2007, 45, 1091-1100.

64. Peeters, R.; Simone, L.; Nelissen, K.; Fabbri-Destro, M.; Vanduffel, W.; Rizzolatti, G.; Orban, G.A. The Representation of Tool Use in Humans and Monkeys: Common and Uniquely Human Features. J. Neurosci. 2009, 29, 11523-11539.

65. Gallese, V. The Inner Sense of Action. J. Conscious. Stud. 2000, 10, 23-40.

66. Johnson-Frey, S.H.; Newman-Norland, R.; Grafton, S.T. A distributed Left Hemisphere Network Active During Planning of Everyday Tool Use Skills. Cereb. Cortex 2005, 15, 681-695.

67. Frey, S.H. Tool use, communicative gesture and cerebral asymmetries in the modern human brain. Phil. Trans. R. Soc. Lond. B. Biol Sci. 2008, 363, 1951-1957.

68. Ramayya, A.G.; Glasser, M.F.; Rilling, J.K. A DTI Investigation of Neural Substrates Supporting Tool Use. Cereb. Cortex 2010, 20, 507-516.

69. Read, D.; van der Leeuw, S. Biology is only part of the story. Philos. T. Roy. Soc. B 2008, 363, 1959-1968.

70. Keller, O. Aux Origines de la Géométrie—Le Paléolithique; Vuibert: Paris, France, 2004.

71. Reber, R.; Winkielman, P.; Schwarz, N. Effects of perceptual fluency on affective judgements. Psychol. Sci. 1998, 9, 45-48.

72. Reber, R.; Schwarz, N.; Winkielman, P. Processing Fluency and Aesthetic Pleasure: Is Beauty in the Perceiver's Processing Experience? Pers. Soc. Psychol. Rev. 2004, 8, 364.

73. Hodgson, D. Evolution of the visual cortex and the emergence of symmetry in the Acheulean techno-complex. C. R. Palevol. 2009, 8, 93-97.

74. Verpooten, J.; Nelissen, M. Sensory exploitation and cultural transmission: the late emergence of iconic representations in human evolution. Theory Biosci. 2010, 129, 211-221.

75. Grill-Spector, K.; Henson, R.; Martin, A. Repetition and the brain: neural models of stimulusspecific effects. Trends Cogn. Sci. 2006, 10, 14-23.

76. Supér, H.; van der Togt, C.; Spekreijse, H.; Lamme, V.A.F. Internal State of Monkey Primary Visual Cortex (V1) Predicts Figure-Ground Perception. J. Neurosci. 2003, 23, 3407-3414.

77. Posner, M.I.; Keele, S.W. On the genesis of abstract ideas. J. Exp. Psychol. 1968, 77, 353-363.

78. Zajonc, R.B. Attitudinal effects of mere exposure. J. Pers. Soc. Psychol. 1968, 9, 1-27.

79. Zajonc, R.B. Emotions. In The Handbook of Social Psychology; Gilbert, D.T., Fiske, S.T., Lindzey, G., Eds.; McGraw-Hill: Boston, MA, USA, 1998; pp. 591-632.

80. Tinio, P.P.L.; Leder, H. Just how stable are stable aesthetic features? Symmetry, complexity, and the jaws of massive familiarization. Acta Psychologica. 2009, 130 241-250.

81. Zaidel, D.W.; Hessamian, M. Asymmetry and Symmetry in the Beauty of Human Faces. Symmetry 2010, 2, 136-149.

82. Fechner, G.T. Vorschule der Äesthtik; Breitkopf \& Härtel: Leipzig, Germany, 1876.

83. Berlyne, D.E. Conflict, Arousal, and Curiosity; McGraw-Hill: New York, NY, USA, 1960.

84. Abraham, F.D.; Sprott, J.C.; Mitina, O.; Osorio, M.; Dequito, E.A.; Pinili, J.M. Judgments of Time, Aesthetics, and Complexity as a Function of The Fractal Dimension of Images formed by Chaotic Attractors. Available at: http://www.blueberry-brain.org/silliman/JEM\%20ms4.htm (Accessed on December 2010). 
85. Jacobsen, T.; Höfel, L. Descriptive and evaluative judgment processes: Behavioral and electrophysiological indices of processing symmetry and aesthetics. Cogn. Affect Behav. Neurosci. 2003, 3, 289-299.

86. Redies, C. A universal model of esthetic perception based on the sensory coding of natural stimuli. Spatial Vis. 2007, 21, 97-117.

87. Halberstadt, J. The generality and ultimate origins of the attractiveness of prototypes. Pers. Soc. Psychol. Rev. 2006, 10, 166-183.

88. Machin, A. The role of the individual agent in Acheulean biface variability - a multi-factorial model. J. Soc. Archaeol. 2009, 9, 35-58.

89. McNabb, J. The visual display hypothesis. Hum. Origins 2011, in press.

90. Pope, M.; Russel, K.; Watson, K. Biface form and structured behaviour in the Acheulean. Lithic Studies Soc. 2006, 27, 44-57.

91. Pope, M.I.; Roberts, M.B. Observations on the relationship between individuals and artefact scatters at the Middle Palaeolithic site of Boxgrove, West Sussex. In The Hominid Individual in Context: Archaeological Investigations of Lower \& Middle Palaeolithic Landscapes, Locales \& Artefacts; Gamble, C., Porr, M., Eds.; Routledge: London, UK, 2005; pp. 81-97.

92. Höfel, L.; Jacobsen, T. Electrophysiological Indices of Processing Symmetry and Aesthetics: A Result of Judgment Categorization or Judgment Report? J. Psychophysiol. 2007, 21, 9-21.

93. Wymer. J. Lower Palaeolithic archaeology in Britain; John Baker: London, UK, 1968.

94. Wymer, J. The Palaeolithic Age; Croom Helm: London, UK, 1983.

95. Roe, D. The Lower and Middle Palaeolithic periods in Britain. Routledge \& Kegan Paul: London, UK, 1981.

96. Photo J. Wymer ${ }^{\circledR}$ 1982. Plate XIII. The palaeolithic age. New York: St. Martins (with permission of the Natural History Museum, London).

97. Radomsky, A.S.; Rachman, S. Symmetry, ordering and arranging compulsive behaviour. Behav. Res. Therapy 2004, 42, 893-913.

98. Dulaney, S.; Fiske, A.P. Cultural rituals and obsessive-compulsive disorder: Is there a common psychological mechanism? Ethos 1994, 22, 243-283.

99. Fiske, A.P.; Haslam, N. Is obsessive-compulsive disorder of the human disposition to perform socially meaningful rituals? Evidence of similar content. J. Nerv. Ment. Dis. 1997, 185, 211-223.

100. Hodgson, D. Art, Perception and Information Processing: An evolutionary Perspective. Rock Art Res. 2000, 17, 3-34.

101. From, Marshall, G.D., Gamble, C.G., Roe, D.A. and Dupplaw, D. 2002. Acheulian biface database. Available at: http://ads.ahds.ac.uk/catalogue/specColl/bifaces/bf_query.cfm, ADS, York.

102. Batchelor, R.K. Evolution, Artefacts, Meaning and Design: The extent to which evolutionary theory can explain how and why humans attribute significance and meaning to the material world and the consequences of this for understanding design. Doctoral Dissertation. London, UK, 2004. Available at: http://dspace.bucks.ac.uk/dspace/bitstream/10239/127/1/01Prelims.pdf. (Accessed on December 2010).

103. Dissanayake, E. Homo Aestheticus: Where Art Comes From and Why; Free Press: New York, NY, USA, 1992. 
104. Dissanyake, E. The Deep Structure of Pleistocene Rock Art: The "Artification Hypothesis" IFRAO Congress. Pleistocene art of the world-Symposium: Signs, symbols, myth, ideology (Pre-Acts), 2010. Available at: http://www.ifraoariege2010.fr/docs/Articles/DissanayakeSignes.pdf (Accessed on November 1, 2010).

105. Oakley, K. Skill as a human possession. In Perspectives on Human Evolution; Washburn S.L., Dolhinow, P., Eds.; Holt, Rinehart, and Winston: New York, NY, USA, 1972; pp. 14-50.

106. Edwards, S.W. Acheulean Evidence. Rock Art Res. 2003, 20, 109-111.

(C) 2011 by the authors; licensee MDPI, Basel, Switzerland. This article is an open access article distributed under the terms and conditions of the Creative Commons Attribution license (http://creativecommons.org/licenses/by/3.0/). 